\title{
A Narrative of Crises from the Perspective of a Young Scholar
}

\author{
Iga Joanna Józefiak
}

The saddest aspect of life right now is that science gathers knowledge faster than society gathers wisdom. ${ }^{1}$

The last several months have been filled more than ever with frustration, emptiness, and a sense of powerlessness. The notion of crisis is deeply embedded in this world. The surrounding reality tends to be perfectly imperfect, in the sense that the human strive for perfection constantly encounters numerous problems. The coronavirus pandemic, however, is a very unique problem. Unlike the notions of financial crisis, increase of the ocean's acidity, or the hurricane that hit a distant place, concepts that are abstract for many people, the COVID-19 pandemic has a truly global dimension, i.e. perceptible and experienced by each and every person. Without belittling other problems or catastrophes, it is difficult to find such a tangible crisis in recent years as the COVID-19 pandemic. The world has been changing beyond recognition in the past few decades. Even a few years make a huge difference when it comes to the development of knowledge, technology, or population size and shrinking space. Certainly, in the past there occurred health problems on a global scale, but the world was a completely different place; less globalized, less connected, less international. Accordingly, the earlier approach to the crisis is no longer correct or effective. The international community must accept the fact that the principles it followed so far are obsolete and require, using youth slang, "a quick update".

The world today has entered an era of disinformation. Despite the so-called fake news being present for at least several centuries, it is the past few decades

1 Isaac Asimov, Isaac Asimov's Book of Science and Nature Quotations, Grove Pr, 1990.

(C) IGA JOANNA JÓZEFIAK, 2022 | DOI:10.1163/9789004472365_021

This is an open access chapter distributed under the terms of the CC BY-NC-NĢ 4J licẹnsénzefiak - 9789004472365 
that made it so widespread due to the common and facilitated access to the Internet. The possibilities for acquiring knowledge in developed countries seem to be endless but the opposite may be true for its quality. Virtual freedom of speech should not be confused with spreading false or unverified information. There exists very little regulation of what the media can claim, let alone individuals. There is a complete flexibility in this regard. Today, anyone can write that two plus two equals five, that a cold shower in the morning heals cancer, or that the virus causing COVID-19 does not even exist. And while in some cases the general knowledge of the public is at a high enough level that the author will rather be disgraced for his lack of knowledge of basics mathematics, in others (especially those related to something new, unknown, and unexplored), it arouses controversy and spreads disinformation. Such a low level of critical thinking is worrying. Modern schools focus on memorizing information from textbooks and reproducing teachers' expectations, but in times of stress or crisis, students are not able to distinguish between facts and manipulation. This leads to a formation of a generation that cannot even check whether the information on the Internet is from a reliable source, let alone being able to reason independently. Today, more emphasis should be put on educating an aware, responsible, and rational society. Critical thinking skills would be particularly useful when it comes to the coronavirus crisis, especially since the actions of the international community are rarely in line with science. Some people may drown themselves in the sea of illusion of a close cooperation between states and various academic or research institutions, however final decisions tend to be dictated by other reasons, as demonstrated by successive examples.

The Polish Minister of Health at one point, in an interview on public television, suggested protective face masks were completely ineffective and useless. When asked for his opinion on the reason why people wear masks, he expressed his incomprehension and full disapproval of this method. A couple of weeks later, wearing masks became obligatory in Poland and the Minister himself placed an order for hundreds of thousands of protective masks, proclaiming this decision to be lifesaving. Moreover, the ordered masks turned out to have a forged certificate, which provokes a reflection on whether the protection of the life and health of citizens was actually the main motivation for this order.

In Poland the first lockdown happened in the middle of the presidential election campaign. The ruling party did not want to declare a state of emergency that would force the election to be postponed. While the whole of Europe was preoccupied with the alarming information from Italy or Spain, Poles waited in suspense for the announcement of the date of the presidential elections. On television, instead of health experts, one could only see politicians convincing 
people about the pandemic being under control and persuading society not to be scared of coronavirus. Such political speeches were daily intertwined with increasingly stringent restrictions. How can one expect a society to obey the rules if such contradictory information and lack of consistency are so evident?

Finally, despite earlier assurances of Polish politicians that the country was well prepared for a pandemic, a full lockdown (in the sense of closing shops, bars, even parks and forests, etc.) was introduced very early. Back then, there were only a few cases of CoviD-19 a day, but people were determined to obey the restrictions. The deep understanding among the society and the will to unite and subordinate could be really felt. However, over time, as people began to notice some contradictory information and lack of logic and consistency presented earlier, they ceased to care or worry. The government began to unfreeze the economy, because it could not afford the long-lasting downtime. As a result, most of the people have changed their approach. They started to think that the pandemic was over and stopped treating the situation with the same gravity and prudence as before. While playing this political and economic game presented above, has anyone thought about science? What do doctors or statistics say? In some states, like Switzerland or Germany, for sure scientific opinions were taken very seriously into account, but not in many others. Well, it is enough to say that currently there are over twenty-five thousand cases in Poland a day.

This lack of consistency, along with basing regulations on political and economic premises rather than on scientific evidence, is very common all around the world. This pandemic has shown that the international community is not all that united, as one would have thought before, and that the lecture about cooperation should be once again attended by representatives of most of the states. This can be supported by a few examples.

Firstly, it is worth having a look at the coronavirus tests. How is it possible that such a global crisis is tackled with such local means? Why is it allowed to have a variety of tests in different countries? How can states compare the number of covid-19 cases if it is openly admitted that some tests are more accurate than others? In recent months, one could hear doubts, especially among young people, about the reliability of the information provided by states. Some argued that the numbers regarding cases or tests were underestimated, others, in turn, believed the fear of pandemic was exaggerated. Where do such contradicting opinions come from? The lack of transparency is to blame, together with the poor international cooperation and non-existent unification of rules at the international level. This absence of relevant and competent information makes people doubt, takes away their trust, and at the same time is a propeller for skeptics and conspiracy theories. The more such inaccuracies 
and contradictions, the weaker the confidence of people at the local level, the worse the further cooperation at the international level. The international community more than ever needs a strong core of trustworthy, fair, and equal states that have honest and supportive relations with their citizens.

Secondly, similar discrepancies apply for precautionary measures. In some countries, such as Switzerland, it was already known in June 2020 that the protective visors are not an effective method of protection against the virus and should not be used interchangeably with masks. In Poland, a few months later, this method of protection is not only still allowed, but also widely used, for example, by the staff of the Warsaw airport. It is worrying to observe how poor the knowledge transfer between the states is. Certainly, the research is made public, but there is no incentive for countries to apply to it. International law by its principles is based on recommendations and voluntary applications, however as soon as there is scientifically confirmed research, it would be much more effective, from the point of view of fighting the pandemic, if certain restrictions were unified in the world and countries were even obliged to comply with them. Some of the readers could now raise concerns about states' independence, equality, or freedom, however, it is not about restricting the freedom or questioning the equality of states, but simply about the necessity to uniformly follow scientific facts and validated research. Under such unusual circumstances as a global fight against an invisible enemy, all the states without exception should be guided primarily by what research and facts say. Of course, there remains a question of what should be considered a valid or sufficiently good quality research that could be acknowledged by the international community. Although there is no standardized and precisely declared rules that would define what credible research means, each field has independent, trust-worthy journals that have existed for many years, which publications are commonly accepted and respected.

Lastly, the manner in which states have closed their borders and implemented travel restrictions reminds one of a game of chess, rather than of the way to protect citizens' health. With one exception - chess tend to be more logical. By this humorous comparison it is worth reflecting on the politics that is being played under the guise of a pandemic. Some countries have introduced quarantines, some in turn have closed their borders completely. Others, such as Greece or Croatia took advantage and opened to attract tourists. At the very beginning of the lockdown, LOT Polish airlines suspended flights from China. Air China, on the other hand, was still allowed to land at the Warsaw Chopin airport a few weeks later. The Polish government introduced the "Flight Home" campaign, which aimed to safely bring Poles from abroad. How much better it would be if countries could count on mutual support and international 
cooperation, instead of inventing such expensive and logistically complicated campaigns? If the actions were really guided by safety reasons, and not by financial motives, the states could conduct a dialogue, negotiate, and help each other, and Poles could get home safely taking a different carrier. The quarantine implementation rules also aroused controversy and were neither completely transparent, nor unified, which was an incentive for some individuals to search for loopholes. If the overriding reason behind such travel restrictions was really to inhibit the spread of the virus, the measures would be introduced evenly. Unfortunately, the pandemic seems to constantly be a pretext for economic and political motives to be brought to the forefront. The COVID-19 crisis has not only struck global health systems, but above all has demonstrated existing economic, social, and political weaknesses. It has exaggerated even the slightest tensions between countries, up to the point that dealing with the pandemic has actually become a pretext for a political game. The younger generation usually observes these political skirmishes with a pinch of salt, sometimes though with a pity, or with an idealized desire and hope for future changes. However, in the face of a global crisis, such political games should be set aside, and all restrictions should be coordinated and based solely on scientific recommendations.

Analyzing the above-mentioned local and international examples allows to perceive that the coronavirus crisis has highlighted the international community's weaknesses particularly in the form of poor cooperation, lack of transparency and consistency, and economic and political plaintiffs preferred over science, which prevents states from building strong, trusting relations with citizens. After such a pessimistic diagnosis, it would be constructive and valuable to think about the solutions, which would allow to better deal with the prevailing pandemic and to prevent similar discrepancies and mistakes in the future.

The first and most important weakness that flashes through all the examples analyzed above is the feeble bond between the actions of the international community and science. Over the last couple of months, the world has been put in a situation of scientific uncertainty with regards to the COVID-19 virus. This is not surprising as reliable research requires financial means and, most importantly, time. However, actions based independently of scientific recommendations (e.g. use of protective visors), no regulations regarding the required quality of tests, lack of specified rules to implement quarantine or travel restrictions, have led to public distrust, which favors conspiracy theories and internal rebellion, especially among young people. International law should be effective, coherent, and transparent enough to build trust among all, taking into account different nations, different religions, different cultures, and different levels of education. The most effective way to build trust with 
individuals is for regulators to meticulously collaborate with science and be very explicit about it. Existing instruments turned out not to be sufficiently effective, as the WHO cannot impose any actions, and its recommendations are often disregarded, or simply fade when juxtaposed with a multitude of other information.

The beginning of this chapter mentioned the era of disinformation and the surplus of low-quality knowledge; problems that seem futile to tackle with. Due to ubiquitous digitization the next generations will be increasingly exposed to fake news and virtual manipulation. The only solution that can balance these disadvantages of modern technology is an adequate education of a society, which is not an action of quick, but certainly permanent, results. Young people must be taught to think independently, to express their own opinion in an argumentative way, as well as to sift online information through a rational sieve. Moreover, international law should regulate the basis on which states act in the event of a global crisis such as a pandemic. The international community has a number of independent, strong scientific institutions which it should trust, and which should constitute the main source of information both those given to individuals and those on the basis of which restrictions are being introduced. The present responsibilities and challenges of the states are therefore to educate, inform, and act in harmony with science.

Eventually, observing the futile efforts of individual countries provokes a reflection on the effectiveness of international law. The law, which has cooperation between states as one of its fundamental principles, has suddenly been ignored in the face of such crisis. States seem to exchange too little information, as if they were not sufficiently trusting each other. Of course, in a world ruled by money, where the overriding goal is economic growth, it is natural for states to compete in discovering a vaccine or finding effective ways to protect citizens. However, annihilating the virus that has affected every country, regardless of the state of the economy, size, or political system, can only be done by all the states playing together in one team. And what kind of team fouls its own players when no one is watching? This metaphor reflects USA withdrawing from the WHO, or certain states disregarding the results of credible research, or implementing quarantine rules based on political relations. It is clear that politics and economics will always play a central role, however having the health and safety of the human species at stake should require a little more international effort with transparent and undisguised cooperation. The young generation can constitute a source of inspiration and set an example. While seeing climate strikes around the world, one can see this enormous determination, power, and faith among millennials. It is a generation of ideals, transboundary values, and joint efforts. Climate change, terrorism, or 
a pandemic - all these are global problems against which it is impossible to win alone. Common problems often unite; therefore, the CoviD-19 pandemic should be turned into something positive, namely better international cooperation and stronger ties.

The current crisis has a completely different dimension from many other political and economic problems of the past. Until now, it was either a fight between one group and another (e.g. in the event of war) or a destruction of the place of living (e.g. Earth's degradation), however it was hard to imagine that in this modern world based on freedom and democracy, people will be forced to destroy relationships and social ties. This crisis showed more than anything before that man is a social being, who truly needs close bonds with others. However, it has also indicated that in this ever-rushing world ruled by money, existing relationships are often superficial, hence so many divorces during the lockdown when people were forced to really spend time and get to know each other. This pandemic has proven to also be an opportunity to work on oneself, on relationships with loved ones, on reevaluating priorities and slowing down. The law can work both for the benefit and disadvantage of citizens. Currently, while all restrictions are introduced to protect physical health, at the same time they devastate mental health. Consequently, there is a growing number of divorces, suicides, and mental illnesses. It is daunting to imagine that future generations will only know the world of social distancing, surrounded by people wearing masks, that they will be afraid to shake hands or get close with others. Physical intimacy lies in human nature and prolonged attempts to limit it are inhuman and have a negative effect on social ties and mental well-being. Therefore, a critical analysis of the last several months in terms of what international law could do differently is necessary to make sure that a similar problem in the future will not have such severe consequences. Out of respect and concern for future generations, the international community should make every effort and go beyond its comfort zone to fill the gaps and activate mechanisms in international law, that will allow it to operate more ably and successfully in the future.

Despite all the challenges and downsides, one positive aspect of the coronavirus pandemic should be perceived, which is the improvement in the quality of the environment. Smog decreased to the extent that the inhabitants of northern India could see the Himalayas again after many decades, dolphins appeared off the coast of Sardinia, greenhouse gas emissions sharply dropped. "Isn't it ironic, when we can't breathe, the planet breaths?" - what a pertinent question asked by the Black-Eyed Peas in their new album. ${ }^{2}$ Very often the

2 Black Eyed Peas, "News Today" accessed 1 July 2021. 
argument of overpopulation is brought forward as a major problem in the fight against climate change, however the coronavirus crisis refuted this argument, as the global population has not been significantly reduced. Instead, the lockdowns contributed to amelioration of the environment without the need to decrease the population size. Restriction of flights and decreased use of vehicles for commuting contributed the most to the reduction of greenhouse gas emissions and improvement of air quality in cities. This forced new lifestyle, with decreased travel and partially remote jobs, could mark a beginning of a permanent behavioral change. It would make society more aware and sensitive to the surrounding environment, and more grateful for simple things like clean air, meetings in person, or the power of embrace.

This chapter has shown some of the international law constraints with regards to the coronavirus pandemic, mainly the weak relationship between international law and science, as well as a clear primacy of politics and economics over scientific research. It has also pointed out a prevailing manipulation across media and among politicians, up to a point where a confused society is no longer able to distinguish between facts and fiction. For this reason, the most crucial task in the next decades is to educate a new generation of informed, aware, and responsible citizens. Analyzing the efforts of different countries shows how resourcefully some of them have coped with the crisis. Unfortunately, the rest have been struggling, and paraphrasing Thomas Reid, ${ }^{3}$ the international system is only as strong as its weakest link, hence the necessity of appropriate cooperation between states, transfer of knowledge, and mutual support. The lack of transparency and consistency showed in numerous examples results in weak relations between states at an international level, as well as between countries and their citizens at a national level, undermines trust, and leads to emergence of a rebellious society full of skeptics and conspiracy theories. What is missing the most to effectively combat the pandemic is an international crisis management body that would serve as an "umbrella" coordinating the actions, that would be recognized and respected by all states and authorized to impose certain standards and reporting methods. Such a mechanism would avoid numerous confusions and discrepancies and would assure that no similar crises will be so impactful in the future. Crises are an inherent part of the world, and it is even expected that in the next decades, due to climate change, the planet will be increasingly affected by extreme weather events or natural disasters. Subsequent struggles are therefore certain and unavoidable, but it is up to current leaders whether they will draw

3 Thomas Reid, Essays on the Intellectual Powers of Man (John Bell 1785). 
conclusions, learn their lessons, and be prepared to effectively cope with similar global misfortunes.

This chapter could not be finished otherwise than with an expression of hope. A crisis like this should be the basis for strengthening the international community. It serves as an opportunity to instill the need to act according to "sustainable development", which can be translated into not behaving selfishly i.e., identifying the committed mistakes, critically addressing the weaknesses and reflecting on the possible changes, and finally acting by taking into account a decent future for the succeeding generations. 